\title{
Optimization of the drilling-and-blasting process to improve fragmentation by creating of a preliminary stress in a block
}

\author{
Khalidilla Yussupov ${ }^{1}$, Saifilmalik Myrzakhmetov ${ }^{1}$, Khairulla Aben ${ }^{2}$, Serhii Nehrii ${ }^{3}$, and Tetiana Nehrii ${ }^{3}$ \\ ${ }^{1}$ Satbayev University, 050013, Almaty, Satpayeva 22a, Kazakhstan \\ ${ }^{2}$ KAZ Minerals, 050020, Almaty, Omarovoi 8, Kazakhstan \\ ${ }^{3}$ Donetsk National Technical University, 85300, Pokrovsk, Shybankova Sq., 2, Ukraine
}

\begin{abstract}
At mining and processing complexes, many parameters today are evaluated from the point of view of the total process from geology to the final product. Changes in certain mining parameters inevitable lead to the changes in the following downstream processes. In this article, the focus is on the ore fragmentation, which is one of the most important parameters in many mines as it affects the downstream ore preparation and processing efficiencies, productivities and costs. In most of the cases, the cheapest way to improve the fragmentation of the ore is by changing the drilling-and-blasting design parameters. It of course increases the mining costs, but at the same time decreases the costs of the following processes, which are normally significantly higher. Therefore, authors of this article propose a new way of optimization of the drilling-and-blasting process by introducing new blast design modifications. Based on the analysis, research of the scientific information and the mining practise, the authors discuss the way of creation of the preliminary stress in the block of the open pit and hence improving fragmentation. Physical experimental blasts in "Belaya Gorka" open pit were performed and shown positive results reflecting a potential for continuation of the research in this direction in the future.
\end{abstract}

\section{Introduction}

Mining industry is very competitive and requires mining companies to constantly improve their processes, costs and safety. From the sustainability point of view, there other environmental and safety issues at the existing mines and potential mining projects as well $[1,2]$. From the technical point of view, many mines have problems with the decreasing grades of the components in their ores, increasing depths, more complex hydrogeological and geotechnical conditions and hence need new approaches to the processes of mining and processing, which today are not considered separately anymore as it was just one or two decades ago. One process affects the other due to their sequential link between each other and of course any implementation should be evaluated taking into account its complex effect on the company as a whole.

Today, the process of intensification of processing (including heap leaching) is done by applying various effects to the ore (physical, mechanical, chemical, biological), most of which are aimed at improving efficiency and reducing the cost of extraction of valuable components. Very often, ore fragmentation becomes one of the most important characteristics [3]. Therefore, for example, to obtain the required particle size distribution for heap leaching, ore coming from the open pit goes through several crushing stages. Of course, such mechanical crushing is expensive and sometimes makes from 8 to $18 \%$ of the total operating costs.

At the same time, the operating cost of the open pit mining is often several times lower than the cost of processing $[4,5]$, respectively, the cost of ore preparation during drilling and blasting operations is cheaper than mechanical preparation [6].

Therefore, it is obvious that the ore fragmentation during the drilling-and-blasting operations at the mining stage affects the following operations at the stage of processing and could give a positive economic effect to the company as whole.

Many technologies are used in the world today to improve the efficiency of blasting. For example, in works $[7,8]$, the authors describe the effect of empty blast holes on the nearest charged blast holes. In both cases, process modeling was performed to understand and describe the stress distribution in the mining block. Also, the authors of [6] do a calculation, where they show that more work done during the drilling and blasting process to improve fragmentation, save energy and work on the downstream processes, which further shows how the increase in the drilling and blasting cost leads to the decrease in the cost of the following crushing and grinding.

Considering that there are several ways to perform research on the new technologies, such as simulations [9], digital twins [10] or actual physical tests at the mines sites, where possible, authors of the work have performed physical blasting experiment at one of the

\footnotetext{
*Corresponding author: abencl@mail.ru
} 
open-pit mines. Of course, at the beginning, all the conditions and actual information on the performance of the mine were gathered for the future comparison with the research work's results.

\section{Research}

Blasting is a complex process, which is still not fully understood, even though a lot of research work is conducted to improve it. Many works are performed at certain conditions, which are hard to be replicated in the mining site, because every blasting block is different and it is impossible to consider the main parameters so that can be utilized as general ones. Knowing that the blasting process has many important characteristics affecting its efficiency, the research work has focused on one of the main ones, which is the stress wave that plays the main role in the mechanism of fragmentation of rocks by blasting.

\subsection{Calculation methods}

The method for calculating the parameters of stress waves was developed by the authors of $[11,12]$. This technique was improved in works $[13,14,15]$, while the author of work [13] tried to take into account the detonation velocity and the actual length of the charge. The considered algorithms and programs were strongly focused on the types of computer technology of that time and were not very suitable for carrying out a large amount of calculations.

He calculated the geometric parameters of the wave front arising around a charge of cylindrical symmetry, introduced and experimentally determined the rate of decrease in the conical section of the wave front. However, at the stage of determining the influence of the design parameters of a charge of cylindrical symmetry on the formation of a stress field in an unlimited medium, he did not take into account such an important parameter as the diameter of the charge. As a result, the calculation he proposed makes it possible to only qualitatively estimate the shape of the wave front, depending on the length of the charge and the detonation velocity.

The author of [14] eliminated these shortcomings, but considered the process of formation of a stress field from an elongated charge, which does not fully describe the real picture of the effect of stresses on the fracturing of a rock mass, since in practice, the blast holes are not blasted separately, but rather as a whole block of the blast holes.

In [15], a method for the numerical calculation of the parameters of the wave field of stresses from four blast hole charges is proposed. However, this technique did not take into account such important parameters of the blast-holes as the direction of initiation, the number of points of initiation. In addition, only radial stresses or stress wave components along the coordinate axes were calculated, which made it difficult to analyze over the entire calculated field.
To improve the quality of the ore to be broken and to reduce the cost of crushing it before leaching, a technology of crushing has been developed using the preliminarily created stressed state of the massif.

In our case, to study the influence of the preliminary stressed state of the massif on the quality of ore breaking, experimental blasts were carried out in the open pit, which has drilling-and-blasting process for the initial ore crushing.

\subsection{Research site}

The object of the study is the section of "Belaya Gorka" site, which is a part of the Rodnikovoye deposit, administratively located in the northern part of the territory of the Kokpektinsky district (on the border with the Zharma district) of the Eastern Kazakhstan region of the Republic of Kazakhstan.

Overall, the technological process at the site is fairly standard for the mining complexes. Mining and processing are performed with a cycle consisting of:

- drilling and blasting with the use SBU-100GA50 drills;

- $\quad$ loading using backhoe excavators with the 2.2 $\mathrm{m}^{3}$ bucket for waste and $1 \mathrm{~m}^{3}$ bucket for ore;

- transportation of the mined ore to the ore stockpiles and waste to the waste dumps using 40 tonnes payload Belaz trucks;

- $\quad$ from the stockpiles the ore is sent to the crusher for preparation;

- $\quad$ prepared ore is sent to the heap leach pad for extraction of gold.

The mine has average grades of approximately 1.44 $\mathrm{g} / \mathrm{t}$. At the same time, because heap leaching is utilized the cost of processing is low, but the recovery is low as well (around 62\%). Other geological and technical conditions of the mine are:

- Average uniaxial compression strengths of the rocks 78.2 $\mathrm{MPa}$ (46-111 $\mathrm{MPa}$ range) in the dry state and 55.6 MPa (5-97 MPa range) in the wet state respectively; - $\quad$ Oxide and sulphide materials are present at the mine;

- $\quad$ Rocks are fractured, but pit walls are stable with some local failures;

- Batter face angles in the pit are $45-60^{\circ}$, with steeper parameters in the eastern $\left(50-55^{\circ}\right)$ and western walls $\left(55-60^{\circ}\right)$;

- Swell factors variate depending on the rock types from 1.27 to 1.75 (1.6 in average);

- $\quad$ Specific gravity also varies from $2.14 \mathrm{t} / \mathrm{m}^{3}$ for the soft weathered material, $2.58 \mathrm{t} / \mathrm{m}^{3}$ for the hard oxidized material and $2.72 \mathrm{t} / \mathrm{m}^{3}$ for the primary hard rocks.

Based on the mining technical conditions of mine, the method of vertical blast hole charges with a short-delayed blasting was adopted. The blasting block that was chosen for the experimental blasts consisted mainly of sandstones and siltstones.

Drilling and blasting parameters were settled at the mine in the previous years of operation. However, some them, like burden, stemming and charge height are variable due to the presence of many different rock types. 
The list of the main blast design parameters are reflected in the table 1 .

Table 1. Drilling and blasting design parameters.

\begin{tabular}{|c|c|c|c|}
\hline Name & Unit & \multicolumn{2}{|c|}{ Parameter } \\
\cline { 3 - 4 } & ore & waste \\
\hline $\begin{array}{c}\text { Sub-bench or bench } \\
\text { height }\end{array}$ & $\mathrm{m}$ & 5 & 10 \\
\hline Blast hole diameter & $\mathrm{m}$ & 0.11 & 0.11 \\
\hline $\begin{array}{c}\text { Explosive density } \\
\text { (grammonite used for } \\
\text { the experimental blasts } \\
\text { in the pit) }\end{array}$ & $\mathrm{t} / \mathrm{m}^{3}$ & 0.9 & 0.9 \\
\hline $\begin{array}{c}\text { Specific gravity of the } \\
\text { rocks }\end{array}$ & $\mathrm{t} / \mathrm{m}^{3}$ & 2.41 & 2.72 \\
\hline $\begin{array}{c}\text { Burden of the first row } \\
\text { of the blast holes along } \\
\text { the bottom of the bench }\end{array}$ & $\mathrm{m}$ & 4.8 & 6.6 \\
\hline Subdrilling & $\mathrm{m}$ & 1.0 & 2.0 \\
\hline $\begin{array}{c}\text { Blast hole depth } \\
\text { (drilling depth) }\end{array}$ & $\mathrm{m}$ & 6.0 & 12.0 \\
\hline Stemming & $\mathrm{m}$ & $3.1-3.4$ & $4.3-4.6$ \\
\hline $\begin{array}{c}\text { Charge height in the } \\
\text { hole }\end{array}$ & $\mathrm{m}$ & $2.9-2.6$ & $7.7-7.4$ \\
\hline $\begin{array}{c}\text { Explosive specific } \\
\text { consumption per } \\
\text { volume of rock }\end{array}$ & $\mathrm{kg} / \mathrm{m}^{3}$ & 0.6 & 0.6 \\
\hline Burden & $\mathrm{m}$ & $3.5-7.0$ & $4.6-8.0$ \\
\hline Spacing & $\mathrm{m}$ & 3.2 & 4.1 \\
\hline
\end{tabular}

The main explosives, which are used at the mine are:

- ANFO for the soft dry areas (mainly overburden and oxide ore);

- FortisExtra 70 for all the other ore and rock types;

- Grammonite is sometimes used as a replacement for the above-mentioned explosives.

SenatelMagnum with the cartridge diameter of 34 or $90 \mathrm{~mm}$ is normally used as a primer. However, in some cases, ammonite with the cartridge diameter of 34 or 90 $\mathrm{mm}$ and trinitrotoluene blocks (T-400) are used as well as a replacement to the SenatelMagnum.

For the conditions of this deposit, the blast holes in the ore blocks is drilled to the depth of 6 meters, so that the amount of explosive per $1 \mathrm{~m}$ of the blast hole is $\mathrm{P}=9.5 \mathrm{~kg}$, the weight of the charge in the blast hole, taking into account stemming height of $3.1 \mathrm{~m}$ is $\mathrm{Q}_{\mathrm{bh}}=27.6 \mathrm{~kg}$.

\section{Discussion}

It is known that the process of fragmentation of rocks by blasting occurs in very quickly and depends on many factors, which are not easy understand and research. There is still no internationally accepted exhaustive theory of the mechanism of fragmentation of rocks by blasting.

Assuming that during the process of blasting, the fragmentation of rocks is mainly determined by the energy of stress waves, the effect of blasting of a single concentrated charge in an unlimited homogeneous medium can be represented in the following form:
- During the blast, the walls of the charging block are instantly affected by the enormous pressure of the blasting products and a shock wave is generated;

- The compression stress at the shock front increases abruptly, the velocity of its propagation exceeds the speed of sound in the rock;

- The crushing resistance of even the toughest rocks is several times lower than the magnitude of the stresses arising at the wave front at the walls of the charged block;

- Particles of the rock receive radial movements and are displaced after the front of the shock wave;

- After the shock wave has passed, the pressure in the charged block drops, and the rock near the charge begins to expand towards the center of the charge and unload;

- As a result, a zone of highly deformed rock is formed;

- As you move away from the charge, the blasting energy is transferred to the ever-increasing mass of the medium, due to which the specific energy $\left(J\right.$ per $1 \mathrm{~cm}^{3}$ of the block) decreases significantly. Compressive stresses drop rapidly with distance.

\subsection{Rock crushing zones understanding}

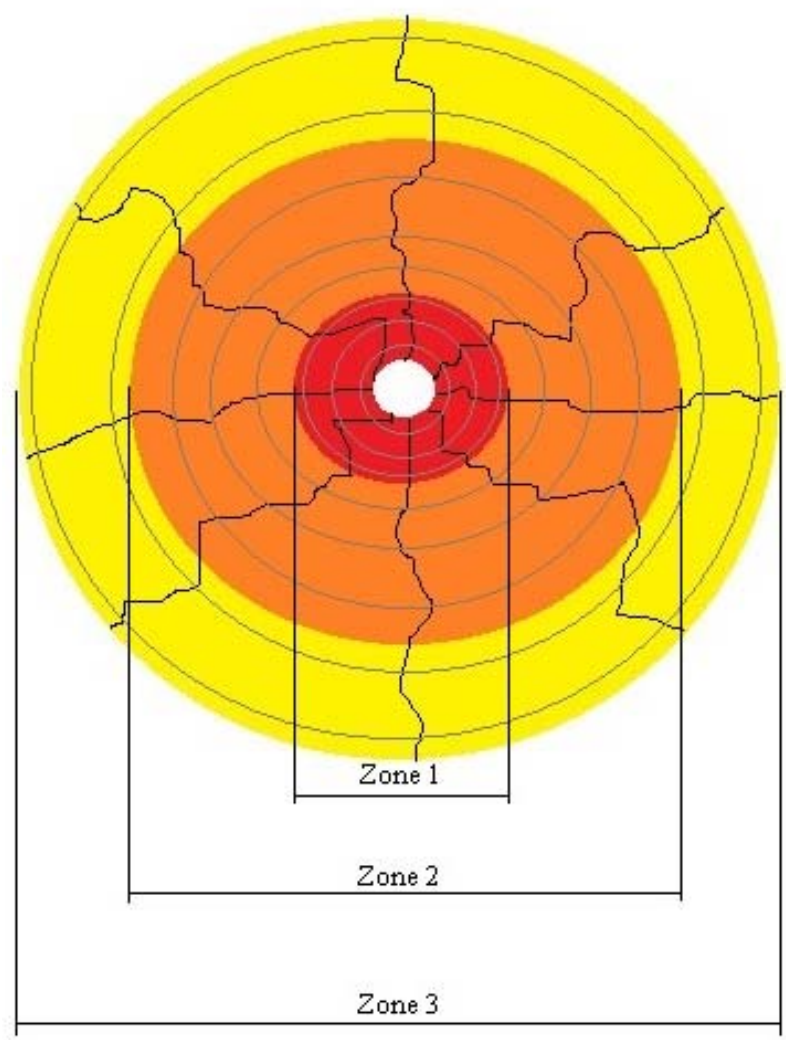

Fig. 1. Various zones arising from hole blasting (red - zone 1, orange - zone 2, yellow - zone 3 .

Thus, when blasting holes in a quarry or pit where hard rocks are mined, several zones are distinguished [16]:

- the first zone is compression and plastic deformation, which, depending on various factors, is usually within 3-7 radiuses of the charge from the blast hole; 
- the second zone - elastoplastic deformations and primary fracturing, in which rocks are crushed when subjected to tangential stresses creating tension. It is usually within 120-150 charge radiuses;

- the third zone is elastic deformation and fracturing, which, respectively, is outside the 150 radiuses of the charge.

All the above-mentioned zones are schematically reflected on the figure 1 .

\subsection{Blasting in a block}

Thus, if we consider a theoretical block consisting of four blast holes located in a row, it can be understood that the least affected area is usually located in the center, at an equal distance from all holes, as shown in Figure 2.

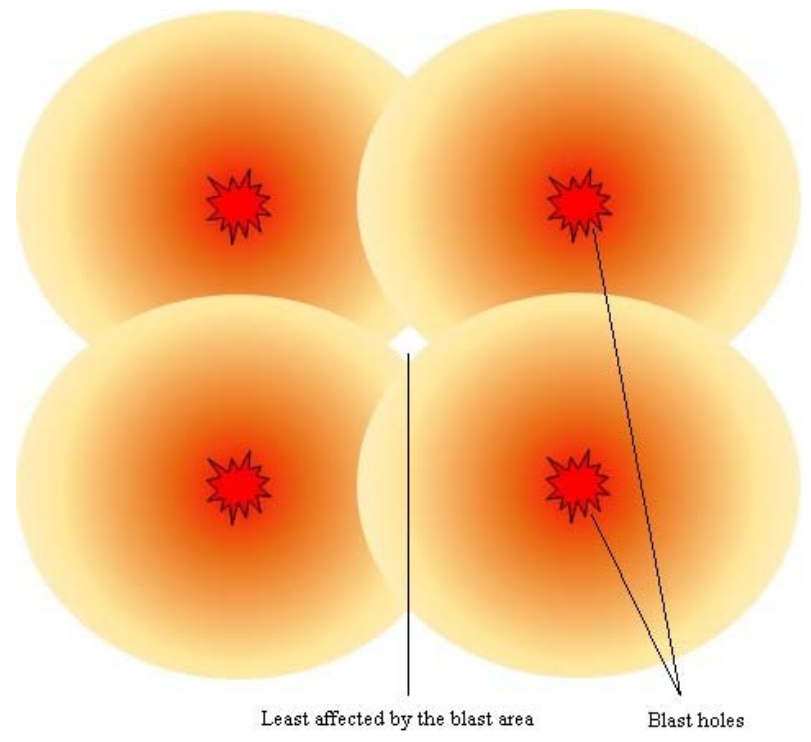

Fig. 2. Theoretical block, showing effect of the blast at the distance from the four holes, where color from red to white shows the intensity of fragmentation (white area in the center is the least affected by the blast)

Considering that, one of the major challenges in the production blasting is to have a rock mass with specific particle size distribution. The solution to this problem is possible by studying the above data, as hole as on the basis of a full research of the mechanisms of fragmentation of the rock, when impulsive loads are applied, which allows us to determine the optimal parameters of the pulse in specific mining conditions.

In our case, two or three rows of blast holes are used in the pit to fragment rocks. According to calculations, knowing the amount of the energy released by $1 \mathrm{~kg}$ of the explosive, and having the such parameters as the weight of explosive in one blast hole from the Table 1, the total potential energy of one hole is equal to:

$$
E_{p}=E_{e} m_{h} 4.1868
$$

where $E_{p}$ - potential energy of the blast per one blast hole;

$E_{e}=1025 \mathrm{kcal} / \mathrm{kg}$ - energy released by $1 \mathrm{~kg}$ of the explosive; $\mathrm{m}_{\mathrm{h}}$ - mass of the explosive in one blast hole.

So, the total potential energy of the blast per blast hole equals to $118444.57 \mathrm{~kJ} / \mathrm{kg}$, with a detonation speed of $3500 \mathrm{~m} / \mathrm{s}$, which is the rate of increase of the initial load on the hole walls.

On one side of the hole, this load is applied to the volume of the rock mass, one side of which is the bench face, i.e. free face, which is not loaded. On the opposite side, the blast shock wave coming from the blasting sets the momentum for the particles of rock. First, the particle velocity is calculated using the formula below:

$$
\vartheta=\sqrt{\frac{2 n q Q}{p}}
$$

where $\eta=0,05$ - blast efficiency coefficient;

$q=0,6$ - explosive specific consumption from the Table $1, \mathrm{~kg} / \mathrm{m}^{3}$;

$Q=4291$ - specific heat of the blast of the specific explosive, $\mathrm{kJ} / \mathrm{kg}$;

$\rho=2410-$ specific gravity of the rock, $\mathrm{kg} / \mathrm{m}^{3}$.

So, the particles velocity for our specific scenario is approximately $0.33 \mathrm{~m} / \mathrm{s}$.

Further, having calculated the velocity of the rock particles during the blast, it is possible to calculate the kinetic energy of the blast, required to throw away the first layer of rock with a volume of $\mathrm{V}=227 \mathrm{~m}^{3}$ using the following formula:

$$
E_{k}=\frac{m \vartheta^{2}}{2}
$$

where $\mathrm{m}=547 \mathrm{t}-$ mass of the $227 \mathrm{~m}^{3}$ of rock of the first row;

$\vartheta=0.33 \mathrm{~m} / \mathrm{s}-$ velocity of the particles of the rock during the blast.

The kinetic energy required to throw away the first layer of rock would be equal to $E_{k}=29.8 \mathrm{~kJ}$. The amount of energy released from the blast hole charge is $\mathrm{E}_{\mathrm{bh}}=118$ $444.57 \mathrm{~kJ}$, which means that a little energy is used for blasting of the first row and the rest of it is dissipated in the other blasting zones, used for the heat generation and etc.

Knowing this, blasting zones can be calculated using the known radius of the charge $(55 \mathrm{~mm}$ as the hole diameter is $110 \mathrm{~mm}$ ) for the specific conditions of the mine:

- Zone 1 is assumed to be 7 charge radiuses and equal to $0.385 \mathrm{~m}$;

- Zone 2 is assumed to be 120 charge radiuses and equal to $6.6 \mathrm{~m}$;

- Zone 3 is assumed to be 150 charge radiuses and more, and equal to $8.25 \mathrm{~m}$.

Having studied in more details the technology of fragmentation of rocks in the open pit, we made a proposal for the classical technology of accounting for the initial stresses obtained from the blasting of the first row of holes, which made it possible for us to clarify the delay time of the second row of blast holes.

Further research of the process of fragmentation of rocks has shown that when the blasting of the second row with a delay, the initial stress is used, only in the section 
between the first and second rows of blast holes, and most of the area is fragmented by crushing the rock using the power of the blast wave, which several times exceeds the ultimate strength of the rock mass. The remaining part has mainly closed cracks, which, when blasting the next row of holes, do not contribute much to crushing. In the interval between the side of the open pit and the first row of blast holes, the rock is crushed by the tension wave, which occurs when the blast wave is reflected from the free surface of the pit wall.

\section{Proposed technology}

To use the initial stress for the purpose of crushing the rock during the blasting of holes in a block, an updated blast design layout of the holes shown in Figure 3 was proposed.

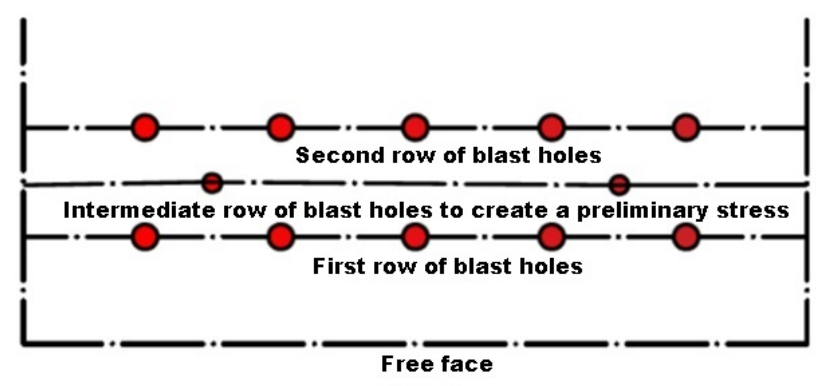

Fig. 3. Proposed holes layout (two standard rows of the blast holes and one intermediate).

In order to create an initial stress in the entire area of the breakage intended for fragmentation, an additional row of charging holes is created, and the blasting power of additional holes should not exceed the ultimate strength of the rocks being crushed. The burden is determined for each case separately, taking into account the mining and geological conditions of the field and the radiuses of the blasting zones. The distance to the additional row of holes and the distance between the holes are selected taking into account the burden of the first row of holes, and all holes along the surface must be at an equal distance from these holes. Thus, an elastic stress wave can be created, which will not fragment the rock, but rather create the initial stresses for the further more homogeneous fragmentation of rock by the main blast. Overall, the assumption is that the best place for the intermediate holes is at the border of the second and the third blasting zones.

The blasting of the first row of blast holes must be made at the moment, when the wave of the firstly blasted row of intermediate holes passes the first row of blast holes and creates an initial preliminary stress. In order to match the timing, the delay time between the intermediate row and the first row of the blast holes should be calculated. The effect obtained with such blast delay will provide interference of stress waves, which will facilitate their action and increase the effect of fragmentation produced in the block.

The delay time (interval) between the initiation of the intermediate and the first row of the blast holes is determined using the following formula: $[17,18]$

$$
t=\frac{\sqrt[2]{a^{2} 4 W^{2}}}{\vartheta_{s}}
$$

where $a$-is the distance between charges, $\mathrm{m}$;

$W$ - burden of the blast holes along the bottom of the bench, m;

$\vartheta_{s}$ - velocity of shock wave propagation in the rock mass, $\mathrm{m} / \mathrm{s}$.

When using the proposed formula above, the average delay should be equal to $32 \mathrm{~ms}$.

\section{Results}

To establish the influence of the initial or preliminary stress on the quality of ore crushing, a new blast design was proposed. The existing blast design of the "Belaya Gorka" site was adjusted with an addition of an intermediate row of blast holes, which were placed at the border of the second and the third blasting zones calculated for the specific conditions of the mine. The purpose of such intermediate row was to create a preliminary stress to improve the final block fragmentation.

After the changes in the blast design, in order to test its effect, limited amount of experimental blasts were carried out in the open pit with the fragmentation analysis of the crushed ore determined immediately after the blasts, at the block in the open pit using photos with the planimetric method of measurements.

As the result, the fragmentation analysis the crushed ore using standard blast design has shown that the amount of pieces of ore up to $300 \mathrm{~mm}$ in size averaged $48 \%$, while the fragmentation with the proposed technology has shown that the amount of the same size pieces averaged at $73 \%$, which meant that the fragmentation has improved by approximately $25 \%$, which exceeded the expected results.

\section{Conclusions}

There is a new technology proposed to improve the efficiency of the fragmentation of rock during the drilling and blasting process in the open pit mines, which considers several important factors of blasting, like:

- zones of blasting;

- charge diameters;

- delays;

- other blast design parameters;

- properties of rock;

- geological and technical conditions of the specific mine.

In order to create an initial stress on the mining block intended for fragmentation, the following technology has been proposed:

- an additional row of charged holes with a certain spacing should be drilled in between the existing rows;

- the holes should be loaded so that the blasting power of them does not exceed the ultimate strength of the rocks to be crushed;

- these additional holes should be blasted first; 
- blasting of the subsequent rows of holes must be carried out taking into account the level of the initial stress of the rock mass, which can be adjusted by the interval of deceleration of blasting depending on the physical and mechanical properties of the rock mass and the radiuses of the blasting zones;

- for the conditions of the "Belaya Gorka" site, the delay interval should be taken as $32 \mathrm{~ms}$, for any other conditions the delay should be recalculated.

Once the intermediate row is blasted, the created by it elastic waves create an initial stress and open and closed cracks, but at the same time do not break the rock. Further, blasting of the first row of blast holes must be performed at the moment, when the wave of the blasted row of intermediate holes passes the first row of blast holes and creates an initial preliminary stress. In order to match the timing a delay time should be calculated. The effect obtained with such blast delay will provide interference of stress waves, which will facilitate their action and increase the effect of fragmentation in the block.

Approximate increase in the works required during the drilling and blasting process due to the addition of an intermediate row of blast holes is 15 to $20 \%$, while as the experimental blast has shown the improvement in the ore fragmentation can be expected at an approximate level of $25 \%$. So, if we take into account that the works during the mining processes are normally cheaper than the works performed during the mechanical ore preparation and processing, we can assume that the additional mining costs will eventually give larger savings in the costs of the downstream processes. So, the results obtained justify the further continuation of the research in this area and a necessity in a wider experimental work with more semiindustrial blasts in the operating mines, in order to perform a calculation of the full economic effect that this technology can provide.

\section{References}

1. S. Nehrii, T. Nehrii, L. Bachurin, H. Piskurska, Problems of mining the prospective coal-bearing areas in Donbas, E3S Web Conf., 123 (2019) 01011, DOI: https://doi.org/10.1051/e3sconf/201912301011

2. R.S. Karenov, Y.D. Orynbassarova, Y.B. Romanko, T.B. Kazbekov, The mining and metallurgical industry of Kazakhstan: Current state of problems, and strategic development priorities, 11, 2239-2254 (2016)

3. S.G. Onika, Modelirovanie seismicheskogo vozdeistviya vzrivov y carere Mikashevichi. Gornaya mechanica and mashinostroeniye, 2, 9-14 (2016)

4. C.Meagher, S.A. Sabour, R. Dimitrakopoulos. Pushback Design of Open Pit Mines Under Geological and Market Uncertainties (2010)

5. M. Asad, , E. Topal, Net present value maximization model for optimum cut-off grade policy of open pit mining operations. Journal of the Southern African Institute of Mining and Metallurgy, 111 (11), 741750

http://www.scielo.org.za/scielo.php?script=sci_artte
xt\&pid=S2225-

62532011001100005\&lng=en\&tlng=en

6. L. Workman, J. Eloranta, The Effects of Blasting on Crushing and Grinding Efficiency and Energy Consumption. Proceedings of the Annual Conference on Explosives and Blasting Technique (2003)

7. Y. Yang, Z. Shao, J. Mi, X. Xiong, Effect of Adjacent Hole on the Blast-Induced Stress Concentration in Rock Blasting, Advances in Civil Engineering, 13 (2018) https://doi.org/10.1155/2018/5172878

8. B. Chen, C. Liu, J. Yang, Design and Application of Blasting Parameters for Presplitting Hard Roof with the Aid of Empty-Hole Effect, Shock and Vibration, 16 (2018). https://doi.org/10.1155/2018/8749415

9. S. Nehrii, T. Nehrii and H. Piskurska, Physical simulation of integrated protective structures, E3S Web Conf., 60 (2018) 00038, DOI: https://doi.org/10.1051/e3sconf/20186000038

10. C. Miskinis, How ore mining will be improved using digital twin simulations, https:/www.challenge.org/insights/digital-twin-inmining/. Dec 2018

11. V.A. Borovikov, I.F. Vanyagin, M.G. Menzhulin, S.V. Tsirel, Volny napryazheniy v obvodnennom treshinovatom massive (Textbook, Leningrad, 1989)

12. I.Yu. Ermolaev Abstract to the dissertation. SaintPetersburg Mining Institute, 1992

13. T.V. Stoyanova, Upravlenie intensivnostyu processa razrusheniya pri otboyke granite na sheben, Dissertation. Saint-Petersburg Mining Institute, 1998;

14. D. Wang. Prikladnaya teoriya uprugosti (Moscow, 1959)

15. V.I. Komashchenko, V.F. Noskov, T.T. Ismailov, Vzryvnie raboty. (Textbook for universities, Higher school, Moscow, 2007)

16. A. Stavrogin, B. Tarasov, Eksperimental'naya fizika i mekhanika gornykhporod. (Nauka, SaintPetersburg, 2001)

17. S.A. Brylov, L.G. Grabchak, V.I. Komashchenko, Gorno-razvedochniye i burovzrivnie raboty. (Nedra, Moscow, 1989)

18. B. N. Kutuzov Vzryvnie raboty. (Nedra, Moscow, 1988) 